\title{
COLECGION LITERARIA
}

\section{Poetas Brasileños Contemporáneos}

$\boldsymbol{L}$ A historia de un pueblo no se registra simplemente en la enunciación de sus hechos guerretos, de sus luchas políticas o religiosas, de sus conquistas $y$ de sus reveses. Existe algo más positivo y convincente, libro abierto al tiempo, que matca un timbre particulat y le afirma en su justo lugar en la naturaleza; es una fuerza intima superior que, en un impulso itresistible, la determina y define sus caracteres; una llama palpitante que la ilumina, le imprime catácter de permanencia sobre la tierta; el alma de la taza.

Amargutas y alegrias, privaciones y glotias, victorias $y$ detrotas, son factores de circunstancias comunes a todos los pueblos, en su muda evolución a través de las edades. Pero el hombre de hoy busca algo en que depositar la presencia de su paso por la tierra, pues que las luchas trastornan el carácter, le hacen adusto, severo, despótico y significan fenómenos pasajeros frente a la influencia que tras sí va dejando el hormigueo humano a través de la lengua sobre la cual nadie más que el poeta ejerce paternidad.

Es cietto que una apatiencia orgánica de progreso fascina a los hombres y les hace creet en las excelencias de determinadas circunstancias, $y$ de ahi que todos los medios científicos o literatios, artísticos o religiosos, formen coro en determinada época y momento. Es que el hombre, producto creado en el curso de luchas azarosas, no olvida su condición humilde, y su humildad humana le torna en esencia en continuador de la cortiente, con facilidad. Se afinca a la tietra $y$ en ella se introduce con profundas taices $y$ trata de atrancarle los medios que necesita en el afán de perpetuat- 
se. Haciendo de la tietra cuna y sepulcro, la engalana con sus mejotes ropajes y le hace participe de sus más caras emociones: herencia mesológica de la que no podtá sustraerse jamás. La tierra es el asiento de su vida, donde el hombre afirma también el trono de su moral y de sus leyes, pues que sabe que debe convivir con semejantes y sus cosas. De ahi que las contingencias eternas le atrastran y los conceptos le dirigen.

Si en realidad una creciente agitación absorbe la inteligencia humana, vatias son sus expresiones, no obstante. Pero el alma de una taza supone ya la formación de un pensamiento general, perteneciente también a todos los demás. Cuando se llega a este grado de civilización nos enconttamos propiamente con una cultura formada y la poesía viene a ser, pues, el gran monumento de la historia que la anima a petfección, celebrando en la obra de patrimonio moral causas muy particulares a cada litetatura.

La literatuta es historia de la propia historia de cada conglometado humano, de cada colectividad. La literatura nos anuncia las grandes revoluciones políticas o religiosas. Profeta del tiempo, llena al mundo con sus enseñanzas y forma la nueva moral ... El verso es el primet hijo del ingenio. A través de él, balbuce el alma de los pueblos. Las primeras manifestaciones apatecen con la primera inquietud de libertad artísticamente expresadas. He ahí la manifestación de un pensamiento inconfundible con el sentimiento: atte y libertad.

Las primicias del amor y la niñez, lo maravilloso de las leyendas; el encanto inédito del suelo natal, predisponen a la poesía, al atrobamiento, a la emoción.

La inspiración poética tiene la semejanza de un soplo creador que penetra y condensa la sustancia amotfa del lenguaje inculto. Los primeros documentos desde las fábulas, a través de las canciones, tomances y trovas, entrañan simultáneamente el primer documento de la evolución artística. Y la poesía es la actividad de esa emoción que se traduce en arte.

Tal vez a la poesía brasileña no pueda aplicársele de hecho este orden de consideraciones. Las primetas expresiones attisticas en el Brasil aparecen en el siglo XIX y toman como formación el descubrimiento de América, para atravesar luego por todas las escuelas comunes a los pueblos europeos que sirven de tema a los periodos fundamentales de discusión entre el clasicismo y absolu- 
tismo literarios, o sea el proceso colonial y el paso a la vida politica independiente.

$Y$ aquí ya se perfila un matcado acento de formación racial en el alma brasileña. El pueblo ingenuo cree apresutadamente, no medita, no precisa, indaga ni resuelve; sueña con la felicidad in mediata o fututa y pone ante cada intertogación, como consuelo a falta de respuesta, la sontisa inmediata de la trova o la lejanía de la canción doliente. Las ideas abstractas repugnan a la filosofía popular; los problemas áridos, las construcciones metafísicas, todo se reduce a mera imaginación. Fantaseat o imaginat para los pueblos es más que una necesidad, es casi un hábito. Todos los países colonizados, patticipes de los beneficios de una civilización trasplantada, cuando las circunstancias les favorecen, estallan en litismo, medio necesario para expresar una emoción. Al llegat aquí ya se encontró un tumbo, un instrumento dúctil a todas las modulaciones de la imaginación y del sentimiento estéticos.

El portugués vernáculo, con sus siglos de antigüedad y una cultura literatia riquisima, habia hecho derroche de colorido y candencia en los ritmos de los viejos cancionetos. Como sector predominante por su cultura en la conquista, ha impreso su sello de paternidad en la formación espiritual de aquel pueblo. Y con la riqueza lírica y la frescura europeas que volcó chorreando sobre un suelo virgen, dejó también la saudade, la melancolía portuguesa que prohijó y fué acentuándose con el curso del tiempo. Esta condición hizo al brasileño el poeta de la melancolía, por la tristeza de las tres razas que intervinieron en la formación de su carácter: el portugués nostálgico, con el tono lánguido de sus fados; el africano, cuya expresión es un grito de dolor y rebeldía ftente al destino aciago a que fué conducido, y el indio, que sufte y lleva en el alma dolorida la queja de los tíos y el murmallo de las selvas mistetiosas. Esta patticularidad ya fué obsetvada por Anchieta, pero ha podido moderarse un tanto con el contacto de otras cultutas y por la disciplina y pulcritud de la poesía portuguesa, que alcanzó en la edad clásica su glotia epopéyica, a través de otros mundos en que esparce su humanismo.

Los primitivos poetas brasiteños expresan esta modalidad en las más vatiadas formas, desde la endecha de amor hasta los cambios de fortuna: motivos tan bellos como la misma vida humana. Pueblo de poetas, cuya grandeza admita, desempeñaron un impor- 
tantísimo papel en su formación las misiones jesuitas, al extremo de suponer un producto de bondad pertinaz y continuos sacrificios que, si bien independizado hoy de elementos artisticos ajenos, tiene una gran obra de teconocimiento.

Pais que emetge a la vida, pletórico de energías, el arte moderno del Btasil se catacteriza por el hotror a lo accesorio, a lo indeterminado, al trivialismo de las producciones fáciles. $Y$ es que toda creación estética de hoy está sometida a una ley de lirismo cerebral. Cabe esperat que el idealismo del siglo XX libere al attista del realismo convencional que momentos culturales anteriores le han impuesto, poniéndolo en contacto con nuestra realidad presente, según el pensamiento de Ronald de Carvalho.

El hombre de hoy que pretende renovar la convivencia hasta de las sociedades humanas, y todo induce a creer que logrará su objeto, ya que no hay fuetza capaz de impedirselo; que aspira a crear nuevos conceptos de libertad y nuevos ptocedimientos para asegutarla, pretende creat también una nueva literatuta, eliminando los preconceptos. Para ello, tiene delante de sí todo un mundo virgen pot descubrit, lleno de promesas incitantes, expuestas a la conquista.

Ir a la búsqueda de ese material, organizarlo y reducitlo a su verdadera expresión humana, debe ser preocupación fundamental del hombre de hoy. Un atte ditecto, puto, profundamente enraizado en la estructuta del nuevo mundo. Un atte que fije todo el tumulto de pueblos en gestación, con sus tremendas sacudidas y con sus tiernos afanes, en la esperanza de resarcirse de su pasado, he ahi lo que compete al hombre del presente.

Estas composiciones traducidas exprofeso pata conocimiento del lector de habla castellana, porque interpretan este pensamiento, suponen la gama de poetas de la hora actual brasileña, en todas sus modalidades, que se acercan a ese futuro. Difícil tesultaría opinat respecto de su valor individual intrínseco en relación de unas con otras. A nuestro juicio cada una de ellas tiene una emoción patticulat, de méritos propios, y todas merecen ocupar un puesto de honot. al lado de las mejores de la lengua cervantina.

Campio Carpio, Buenos Aires. 